Locock, C. (1857) Discussion of paper by E. H. Sievking. Analysis of fifty two cases of epilepsy observed by the author. Lancet, $i$, 527.

Miller, H. CRichton (1920) Functional Nerve Disease. London: Henry Frowde and Hodder and Stoughton.

MitChell, S. WeIR (1905) Some personal observations on the Civil War. Transactions of the College of Physicians, Phila, 27, 88-94.

\section{Park Gate}

D. F. SCOTT

Blackheath

London SE3 9XF

Lithium augmentation in antidepressant-resistant patients

SIR: Austin et al (Journal, October 1991, 159, 510514) recently presented their meta-analysis of five placebo-controlled trials of lithium augmentation in depressed patients "resistant to a standard trial of an antidepressant". They concluded that lithium augmentation had significant efficacy in these patients. However, as the authors acknowledged, while the statistical procedure used to arrive at their conclusions may be 'elegant', its utility is limited by the quality of data being analysed.

Two issues deserve further discussion. The first relates to the duration of antidepressant medication before a patient can be considered treatmentrefractory. The studies reviewed used antidepressants for a minimum of three weeks before adding lithium. However, there is evidence (Quitkin et al, 1984; Georgotas et al, 1986) that up to $25 \%$ of patients treated with an adequate dose of antidepressant medication will not respond until weeks four to six of treatment. Given that many of the patients used in the meta-analysis were prescribed lithium after only three weeks, one has to question whether clinical improvement was attributable to lithium or was, in fact, a delayed response to the primary antidepressant. Dr Austin et al state that "it is doubtful that many clinicians would in practice wait more than four weeks before changing to another treatment if no response is seen". However, if the evidence suggests that six weeks is required for an adequate trial of an antidepressant, then it is incumbent on the clinician to persist with that treatment rather than prematurely adding another medication with its own risks and side-effects.

The second issue pertains to the criteria used to define response to lithium augmentation. Three of the five studies used $a \geqslant 40-50 \%$ reduction in Hamilton Rating Scale for Depression (HRSD; Hamilton, 1960) score and a fourth study used $a \geqslant 2$ point decrease on a 15-point nurses rating scale. Given that the mean HRSD entry scores for those studies ranged from 20-34, many patients fulfilling criteria for response could still have had scores consistent with mild to moderate levels of depression. Therefore, in these studies, response did not necessarily equate with remission of the depressive illness.

Given these considerations, we must await further studies to determine the value of lithium augmentation in the management of patients meeting current criteria for refractory depression (Guscott \& Grof, 1991). At present, there are insufficient data to support the optimistic conclusions of Dr Austin and colleagues.

Georgotas, A., McCue, R., Hapworth, W., et al (1986) Comparative efficacy and safety of MAOIs versus TCAs in treating depression in the elderly. Biological Psychiatry, 21, 1155-1166.

GuscoTT, R. \& GROF, P. (1991) The clinical meaning of refractory depression: a review for the clinician. American Journal of Psychiatry, 148, 695-704.

HAmilton, M. (1960) A rating scale for depression. Journal of Neurology, Neurosurgery and Psychiatry, 23, 56-62.

Quirkin, F. M., RABKIN, J. G., Ross, D., et al (1984) Duration of antidepressant drug treatment. What is an adequate trial? Archives of General Psychiatry, 41, 238-245.

Department of Psychiatry

Alastair Flint

Toronto General Hospital

Toronto

Canada MSG 2 C4

\section{Schizophrenia among Afro-Caribbeans}

SIR: In discussing the higher risk of diagnosed schizophrenia among the British-born African-Caribbean community, Wessely et al (Journal, December 1991, $159,795-801)$ state that the increase is not due to brief reactive psychosis as has apparently been suggested. As far as we know, no one has applied this argument to British-born patients of AfricanCaribbean origin. It was originally suggested to explain high rates of schizophrenia among migrants from the rural West Indies who were not found to have Schneider's first rank symptoms of schizophrenia (CATEGO $\mathrm{S}+$ ) on project diagnosis (Littlewood \& Lipsedge, 1981), and indeed the notion of bouffée délirante has been most typically developed in studies in peasant communities. Nevertheless, their use of the RDC minimum period of illness for schizophrenia (two weeks) would not include any patients satisfying our Jasperian criteria of 'reactivity' (ibid).

As they point out, our current interpretations involve a complex interplay between the biological and the political: simple 'misdiagnosis', with its implications for better education of psychiatrists, is 